
nicians are blocking the road to prehistoric research, as the
Hebrews formerly did.
HYDE CLAKKE

32, St. George's Square, S.W.

\section{Earthquake Waves}

THE observations at p. 385 , on the operation of self-resisting tide-gauges of the U.S. Coast Survey, in illustrating the phenomena of earthquake waves, suggest the expediency of the same means being adopted in the basin of the Mediterranean. This could possibly, by a little correspondence and agitation, be effected at Naples, Athens, Constantinople, and Alexandria. The Turkish and Egyptian Governments are very likely to listen to any representations on behalf of the cause of science. Although the Mediterranean is considered tideless, there is a daily fluctuation of two feet in parts of the Levant, but what is material is that earthquake waves are known to have been manifested at Smyrna.

If our Government could be induced to encourage observations at Gibraltar and Malta, we should obtain a combination of points of contact for two allied regions.

\section{Hyde Clarke}

\section{Spectrum of Aurora}

I wisH to make a correction with reference to my observations on the spectrum of the aurora, as given by $\mathrm{J}$. R. Capron on p. 182 ; for he has credited them with greater accuracy than they profess to have: I have no doubt that my line No. 5 , seen at wave-length 500 or 510 , is the same as Lord Lindsay's and Elger's No. 4, and probably as Procter's. This is the more likely, seeing that the two former placed the principal line much nearer the red end than I did; for I assumed Angström's position $\left(55^{67}\right)$ to be correct. This leaves but one observer of No. 5 (Barker), and possibly his line also is the same; in that case his No. 4 will be the same as Lord Lindsay's No. 3 .

I have seen published the following determinations of the positions of the auroral lines, in addition to those J. R. C. has given :-

No. 2. O. Struve . . . . . . . . . . 5545

Angström . . . . . . . . . . . 5567

German North Polar expedition . . . . . 5569

Peirce (as reported by Winlock). . . . . 557

Respighi .. . . . . . . . . 5573

R. J. Ellery . . . . . . . . . . . 560

No. 3. Peirce has two lines near here- -5315 and 5205 ; the latter is probably Lord Lindsay's "line near E," and possibly A. Clark, Jun.'s line also.

No. 6. Peirce

Wavelength.

$\cdot .+431$ Peirce also gives lines at 545 and 486 .

My latest determinations from my own observations are as follows :-

$$
\begin{aligned}
& \text { Wave-length }
\end{aligned}
$$

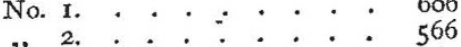

$$
\begin{aligned}
& \text { " } 3 . .5 . . .0 .55165 \\
& \text { " } 4 . .9 . . .5015
\end{aligned}
$$

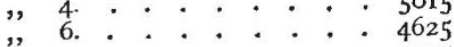

$$
\begin{aligned}
& \text { " 7. . . . . . . . . } 4305
\end{aligned}
$$

I have never seen a line at 532 again.

As to the continuous spectrum, it reaches from No. 2 to No. 7 , being brightest from a little beyond No. 2 to No. 6 . This part of the spectrum does not give me so much the idea of a true "continuous spectrum broken up by dark bands," as of a scr:es of bright bands too close to be distinguished.

Sunderland

T. W. BACKHouse

\section{Spectrum of Nitrogen}

IN a paper communicated to the Royal Society by $\mathrm{Mr}$. Arthur Schuster, it is stated that the line spectrum of nitrogen may be obtained under all pressures and temperatures if every trace of oxygen be removed by heating sodium in the vacuum tube.

I should be glad to learn whether any of your readers have successfully treated Mr. Schuster's experiments.
My friend, Mr. Lee, and myself have, on several occasions, attempted to do so, but always without success.

On heating the sodium we invariably find that an increase of pressure takes place from the liberation of hydrogen which, although very greatly lessened, is not entirely removed by drying the gas with sulphuric acid. On again exhausting we obtain, with the simple current, a spectrum of lines, not of nitrogen, but, in every instance, those of the second so-called hydrogen spectrum first described by Plucker, and afterwards noticed by Wullner and Angström.

This spectrum disappears as soon as the Leyden jar is used, and only the ordinary hydrogen spectrum is then visible.

The only effect which the sodium appears to produce is the liberation of hydrogen; for the same line spectrum can be obtained by exhausting a tube filled with hydrogen, or even with unpurified atmospheric air.

I was struck by the fact that only a few of the lines given by $\mathrm{Mr}$. Schuster in his table of wave-lengths coincide with those of the known spectrum of nitrogen, while many of its most brilliant lines, including that which is its chief characteristic, the double green line (wave-length 5005-5002, Thalen) are not represented in his spectrum.

That the line spectrum of nitrogen can be obtained at all pressures, has been shown in a paper by Mr. Lee and myself, which has been scnt elsewhere for publication; but that it can be obtained at all temperatures, by which, I presume, Mr. Schuster means either with or without the Leyden jar, is certainly contrary to our experience.
Liverpool
C. H. STEARN

\section{Instinct}

\section{The Heredity of Instincts}

THe following may perhaps serve as a contribution to the question so much discussed of late concerning the transmission or acquirement of likes and dislikes amongst the lower animals. It is an extract from a letter of a brother of mine, an officer in India :-

"I have at present a little tiger-cub, about the size of a spaniel, a most interesting pet, though it will soon be a dangerous one. He made friends at once with my fox-hound puppies, and romps with them incessantly. When he sees a cow or a goat his real nature betrays itself. He has no fear whatever of any dog; but, strange to say, is thrown into a parox. "sm of terror at the sight of a kitten or a tiger-skin."

This hardly seems to bear out the assumption so commonly made, that manifestations of this kind must have a history in the experiences if not of the animal itself, at least of its ancestors. We can hardly suppose the parents of this cub to have adopted a frame of mind respecting the race of tigers equivalent to misanthropy amongst ourselves, and the experience of cats or kittens must be small indeed in the jungles of the Decan.

St. Asaph, N. Wales

J. G.

\section{Sense of Direction}

IN Mr. Darwin's article in NATURE for last week there is a passage about " the sense of direction being sometimes suddenly disarranged," that brought to my mind assertions I had fre zuently heard made when travelling some years back in the wild parts of the State of Western Virginia. It is said that even the most experienced hunters of the forest-covered mountains in that unsettled region are liable to a kind of seizure; that they may "lose their head" all at once, and become convinced that they are going in quite the contrary direction to what they had intended, and that no reasoning nor pointing out of landmarks by their companions, nor observations of the position of the sun, can overcome this feeling; it is accompanied by great nervousness and a general sense of dismay and " upset ;" the nervousness comes after the seizure, and is not the cause of it. I was present in a company of hunters when a tale of this "getting turned round " was told as a good joke against one of the party - a Nimrod of renown-the leading features of which he was reluctantly obliged to confess to the truth of, while denying some minor points that had been added to embellish it, as making him more ridiculous than he was : it would take up too much of your space to tell the particulars of the story. The feeling is described as sometimes ceasing suddenly, and sometimes wearing away gradually. Would it not be strange if it should appear that there is a "sense of direction" other than an acquired sense of 